\title{
Reliability of Metal 3D Printing with Respect to the Marginal Fit of Fixed Dental Prostheses: A Systematic Review and Meta-Analysis
}

\author{
Soohyun Bae ${ }^{1}$, Min-Ho Hong ${ }^{2}$, Hyunwoo Lee ${ }^{3}\left(\mathbb{D}\right.$, Cheong-Hee Lee ${ }^{1}$, Mihee Hong ${ }^{4}$, \\ Jaesik Lee ${ }^{5}$ and Du-Hyeong Lee ${ }^{1,6, *(D)}$ \\ 1 Department of Prosthodontics, School of Dentistry, Kyungpook National University, Daegu 41940, Korea; \\ hyun5601@knu.ac.kr (S.B.); chlee@mail.knu.ac.kr (C.-H.L.) \\ 2 Department of Dental Laboratory Science, College of Health Sciences, Catholic University of Pusan, \\ Busan 46252, Korea; mhhong@cup.ac.kr \\ 3 Department of Dental Clinic, National Medical Center, Seoul 04564, Korea; surgeonlee@nmc.or.kr \\ 4 Department of Orthodontics, School of Dentistry, Kyungpook National University, Daegu 41940, Korea; \\ mhhong1208@knu.ac.kr \\ 5 Department of Pediatric Dentistry, School of Dentistry, Kyungpook National University, Daegu 41940, Korea; \\ leejs@knu.ac.kr \\ 6 Institute for Translational Research in Dentistry, Kyungpook National University, Daegu 41940, Korea \\ * Correspondence: deweylee@knu.ac.kr; Tel.: +82-53-600-7676
}

Received: 15 September 2020; Accepted: 19 October 2020; Published: 26 October 2020

\begin{abstract}
Three-dimensional (3D) printing technologies have been widely used to manufacture crowns and frameworks for fixed dental prostheses. This systematic review and meta-analysis aimed to assess the reliability of the marginal fit of 3D-printed cobalt-chromium-based fixed dental prostheses in comparison to conventional casting methods. Articles published until 25 June 2020, reporting the marginal fit of fixed prostheses fabricated with metal 3D printing, were searched using electronic literature databases. After the screening and quality assessment, 21 eligible peer-reviewed articles were selected. Meta-analysis revealed that the marginal gap of the prostheses manufactured using 3D printing was significantly smaller compared to that manufactured using casting methods (standard mean difference (95\% CI): $-0.92(-1.45,-0.38) ; \mathrm{Z}=-3.37 ; p=0.0008)$. The estimated difference between the single and multi-unit types did not differ significantly $(p=0.3573)$. In the subgroup analysis for the measurement methods, the tendency of marginal discrepancy between the $3 \mathrm{D}$ printing and casting groups was significantly different between articles that used direct observation and those that used the silicone replica technique $(p<0.001)$. Metal 3D printing technologies appear reliable as an alternative to casting methods in terms of the fit of the fixed dental prostheses. In order to analyze the factors influencing manufacturing and confirm the results of this review, further controlled laboratory and clinical studies are required.
\end{abstract}

Keywords: metal; 3D printing; reliability; marginal fit; fixed dental prosthesis; systematic review; meta-analysis

\section{Introduction}

Three-dimensional (3D) printing is a process wherein a product is manufactured using layering materials from 3D digital data [1,2]. This process enables the fabrication of sophisticated customized products without complicated laboratory manual works, unlike conventional manufacturing methods [3]. Powder bed fusion is a form of a 3D printing technology commonly used for metal 3D printing $[4,5]$. This technology is also referred to as selective laser sintering (SLS), selective laser melting 
(SLM), direct metal laser sintering (DMLS), or electron beam melting (EBM) in the literature [6,7]. During the procedure of powder bed fusion, a high-powered laser beam is directed at the layer of metal powder following the design of an object and fuses the powder particles sequentially until the 3D object is completely formed [8]. The main differences between the metal 3D printing technologies are operational parameters and post-treatment processes $[9,10]$.

Cobalt-chromium ( $\mathrm{Co}-\mathrm{Cr}$ ) alloys are primarily viable for metal 3D printing in dental prostheses [4]. These alloys demonstrate good tensile strength, elasticity, fatigue resistance, or corrosion resistance [11]. The major constituents of the powder are cobalt and chromium; however, molybdenum, tungsten, silicon, manganese, niobium, cerium, iron, and carbon are also included to improve the properties of the material [9]. Chromium increases corrosion resistance by forming a passivation film; molybdenum influences the grain size and decreases the susceptibility to pitting corrosion; tungsten causes solid solution strengthening with molybdenum; silicon and manganese are inserted to enhance the alloy's fluidity; and niobium affects the intermetallic phase formation and solution strengthening. Generally, the particles used in the powder bed fusion must be approximately 3-14 $\mu \mathrm{m}$ in size [10], and the products are characterized by the anisotropic $\gamma$-phase and $\varepsilon$-phase [12]. Gold and titanium alloys can be processed with the powder bed fusion technology; however, this method is rarely used in dental prostheses owing to the higher cost and mechanical properties [8].

Metal 3D printing technologies have been increasingly used in the field of dentistry for the manufacturing of crowns and frameworks of fixed dental prostheses; however, the accuracy of 3D-printed dental prostheses has not been fully elucidated. Although previous experimental and review trials have compared the accuracy of $3 \mathrm{D}$ printing and conventional fabrication methods, the comparisons were limited to individual settings and descriptive analyses $[6,7,13]$. In the evaluation of the prognosis of fixed prostheses, an acceptable marginal fit is considered a key criterion that influences the clinical success of prostheses [14]. A large marginal discrepancy can influence the cement dissolution and plaque accumulation along the margins, potentially causing secondary caries, inflammatory marginal gingivitis, or prosthesis loosening [15]. The purpose of this systematic review and meta-analysis was to review the reliability of the marginal fit of the $\mathrm{Co}-\mathrm{Cr}$ based fixed dental prostheses fabricated using metal 3D printing technologies in comparison with conventional casting methods.

\section{Materials and Methods}

\subsection{Search Strategy}

This systematic review was designed as per the "Preferred Reporting Items for Systematic Reviews and Meta-Analyses" (PRISMA) guidelines [16]. The review was processed to answer the primary population, intervention, comparison, and outcome question [17]: in the fabrication of fixed dental prostheses $(\mathrm{P})$, are the $3 \mathrm{D}$ printing methods $(\mathrm{I})$ as reliable as the conventional casting method $(\mathrm{C})$ in terms of marginal fit $(\mathrm{O})$ ?

The electronic search was performed on 25 June 2020, using the following databases: PubMed, Scopus, Cochrane, and Science Direct, and were limited to articles published in English only. The formulated search strategy included the use of Medical Subject Heading terms and free-text words with Boolean operators (AND or OR): ("metal"[tiab] OR "alloy"[tiab]) AND ("3D printing"[tiab] OR "additive manufacturing"[tiab] OR "SLS"[tiab] OR "DMLS"[tiab] OR "SLM"[tiab]) AND ("accuracy"[tiab] OR "fit"[tiab] OR "adaptation"[tiab]). A direct online search was performed in order to identify additional articles on Google Scholar.

\subsection{Inclusion and Exclusion Criteria}

In the present review, we included original studies that evaluated the marginal fit of the Co-Cr-based complete-coverage prostheses, including single and multiple units. The eligible studies included in vitro, in vivo, and clinical studies, irrespective of the experimental design. The studies 
were required to have quantitative results of the marginal fit that were recorded as the marginal gap and the absolute marginal discrepancy. The studies that evaluated partial-coverage prostheses, different materials, and other 3D-printed objects, such as dental implants, removable dentures, and artificial bones, were excluded. Narrative reviews, case reports, and studies that did not include a control group with a casting method were excluded as well. The inclusion and exclusion criteria used in this meta-analysis are described in Table 1.

Table 1. Inclusion and exclusion criteria used in the meta-analysis.

\begin{tabular}{cc}
\hline Inclusion Criteria & Exclusion Criteria \\
\hline Study Design & Study Design \\
\hline In vitro study & Case report \\
\hline In vivo study & Animal studies \\
\hline Clinical trial & Narrative review \\
\hline Comparative study & Only charts and questionnaires \\
\hline Evaluation study & Contents \\
\hline Contents & Assessing only the whole or internal fit \\
\hline Assessing marginal fit & Direct restorations and partial-coverage prostheses \\
\hline Complete-coverage prostheses & 3D printing of dental implants, removable dentures, and artificial bones \\
\hline 3D printing using cobalt-chromium alloy & 3D printing using titanium and gold alloys \\
\hline
\end{tabular}

\subsection{Study Selection and Data Extraction}

Two independent reviewers (S.B., and D.-H.L.) screened the studies as per the aforementioned inclusion and exclusion criteria. A calibration exercise with the two reviewers was conducted to increase the reliability of data collection. First, the searched articles were screened as per their titles and abstracts; thereafter, the full text was read after both the reviewers had agreed to the relevance of an article. Disagreements between the reviewers were resolved via discussion. The Cohen kappa coefficient was calculated to determine the final agreement between the reviewers. Subsequently, the characteristics of the eligible studies were extracted from the studies and tabulated in a spreadsheet (Excel; Microsoft, Redmond, WA, USA). The following details were recorded: name of the first author, year of publication, 3D printing device, material, abutment type, prosthesis type, cementation space between the prosthesis and abutment, measurement parameter, measurement method for the marginal gap, sample size, and the value for the marginal fit. While collecting the marginal fit data, the absolute marginal discrepancy (the distance between the most external point of the prosthesis margin and the finish line of the abutment) was first determined as the outcome parameter. When the value was not provided, the marginal gap (the perpendicular measurement from the internal surface of the crown to the margin of the abutment) was recorded.

\subsection{Quality Assessment}

The quality of the included studies was assessed using the Quality Assessment Tool for Diagnostic Accuracy Studies-2 (QUADAS-2) [18]. The four domains for risk of bias assessment were as follows: patient selection, index test, reference standard, and flow and timing. When at least one domain was rated as high risk, the study was considered to have a high risk of bias in its overall judgment. When more than two domains were scored as unclear, the study was regarded as having an unclear bias risk. The traffic-light plots of the specific domain judgments for each study were drawn within each bias domain using the ROBVIS package for R ( R software v.3.6.0; R Foundation for Statistical Computing Platform, Vienna, Austria) [19]. 


\subsection{Data Analyses}

The standard mean difference (SMD) between the prostheses fabricated using 3D printing and those fabricated using casting methods in each study was calculated with the following equation:

$$
\mathrm{SMD}=\frac{\text { Difference in the mean values of the groups }}{\text { Standard deviation of the measurements }}
$$

A value of 0 for the SMD indicated that the two fabrication methods produced the prostheses with the same marginal accuracy.

The heterogeneity among the studies was evaluated using the $\mathrm{I}^{2}$ statistic, $\tau^{2}$, and $p$ value $(\alpha=0.05$; $\mathrm{I}^{2}>50 \%$ was considered to indicate heterogeneity). Based on the resulting heterogeneity, a fixed or random effects model was selected for the meta-analyses of the SMD data. The overall estimate of the SMDs was computed with the inverse variance weighted method, and the effect size estimates were adjusted as per the Hedges method [20]. Subgroup analyses of the SMDs were performed for the different types of prostheses (single and multi-unit) and the measurement methods for the marginal fit (direct observation and silicone replica technique). Publication bias was first assessed by inspecting the asymmetry of the meta-analysis results in a funnel plot. Egger's linear regression test of the funnel plot was then contacted to calculate the statistical value of publication bias. All the meta-analyses were performed using the Meta package for R (R software v.3.6.0; R Foundation for Statistical Computing Platform, Vienna, Austria).

\section{Results}

\subsection{Search Results}

The database and manual search initially identified 142 articles. After excluding 12 duplicate articles, 130 articles were screened by reviewing their titles and abstracts. After the exclusion of 91 irrelevant articles, 38 studies were then evaluated for further eligibility. With full-text reading, 17 articles were further excluded as per the inclusion and exclusion criteria; thus, finally, 21 articles were included in the meta-analysis [21-41]. The strength of the inter-reviewer agreement for the whole screening process was moderate $(\kappa=0.463, p=0.010)$. The search results are described in the PRISMA flow diagram (Figure 1).

\subsection{Characteristics of the Included Studies}

The characteristics of the 21 included studies are summarized in Table 2. In most of the articles, the fit accuracy was investigated on tooth-like abutments; however, there were three studies that used implant abutments. Sixteen studies investigated the fit of single crowns, and five evaluated the fit of a multi-unit fixed dental prosthesis. The mean cement space setting was $35.5 \mu \mathrm{m}$ (range: $20-70 \mu \mathrm{m}$ ) in 16 studies, excluding the studies that did not provide the set value. In the measurement parameter, two studies showed both the absolute marginal discrepancy and marginal gap values; the other studies showed the marginal gap value alone. In terms of the measurement method for the marginal fit, 11 studies used the silicone replica technique, seven used direction observation, two used mechanical sectioning, and one used a computer-aided digital technique. The sample size in each group was about 10-20 in most studies, except one study that used 110 specimens. 


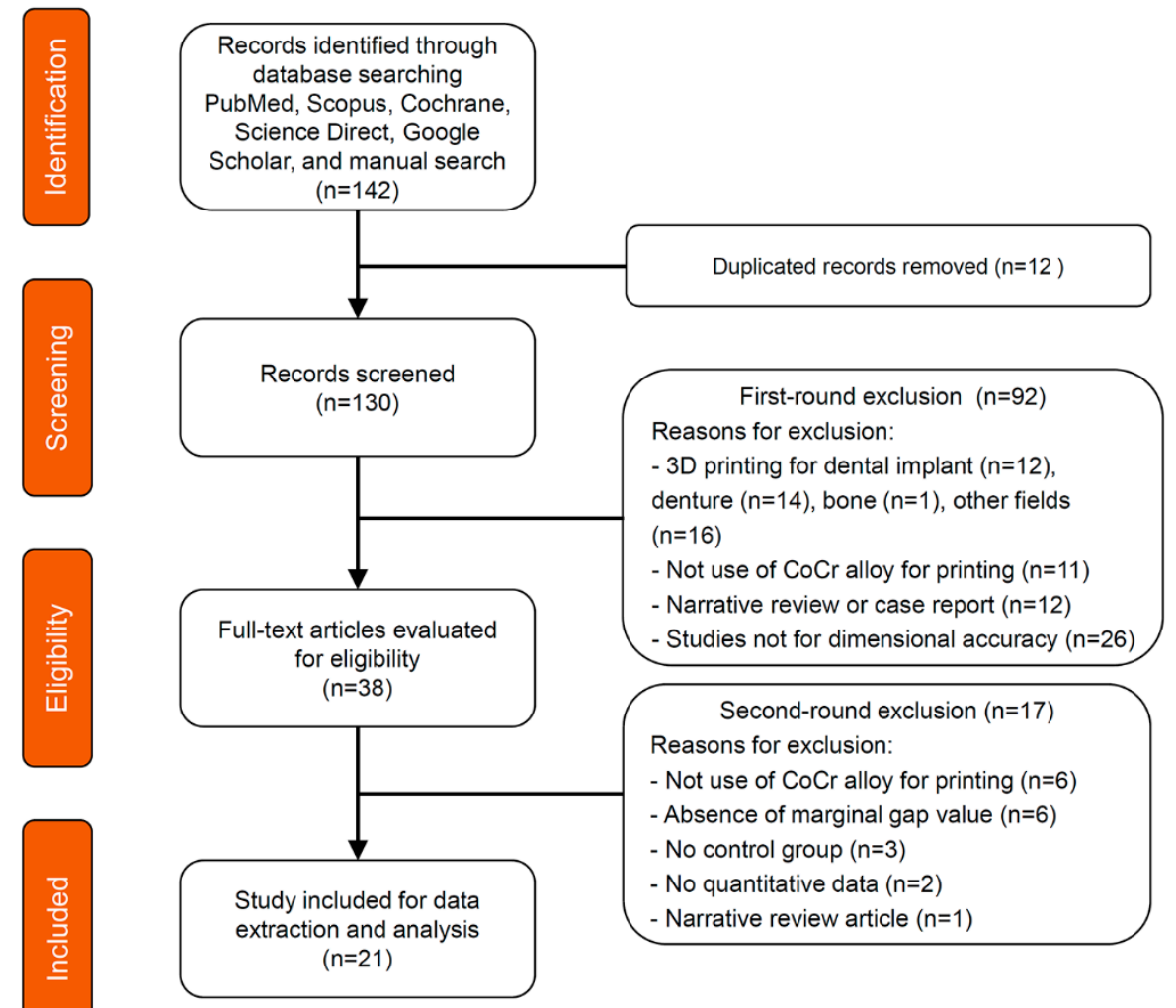

Figure 1. PRISMA flow diagram of the literature search.

Table 2. Characteristics of the included studies $(n=21)$.

\begin{tabular}{|c|c|c|c|c|c|c|c|c|}
\hline \multirow[b]{2}{*}{ Study } & \multicolumn{2}{|c|}{ 3D Printing } & \multirow[b]{2}{*}{$\mathbf{A b}$} & \multicolumn{2}{|c|}{ Prosthesis } & \multicolumn{2}{|c|}{ Measurement } & \multirow[b]{2}{*}{$\mathbf{N}$} \\
\hline & Device & Material & & Type & Space & Gap & Way & \\
\hline Chang 2019 [24] & EOSINT M270, EOS & Wirobond C+, Bego & $\mathrm{T}$ & S & 30 & MG & $\mathrm{CD}$ & 10 \\
\hline Yildirim 2019 [21] & EOSINT M270, EOS & EOS CoCr SP2, EOS & I & S & 25 & MG & SR & 12 \\
\hline James 2018 [25] & EOSINT M270, EOS & EOS CoCr SP2, EOS & $\mathrm{T}$ & $S$ & 25 & MG & SR & 10 \\
\hline Ullattuthodi 2017 [27] & EOSINT M270, EOS & $\mathrm{N} / \mathrm{P}$ & $\mathrm{T}$ & S & 50 & MG & DO & 10 \\
\hline Kocaağaoğlu 2016 [30] & EOSINT M270, EOS & EOS CoCr SP2, EOS & $\mathrm{T}$ & S & 30 & MG & SR & 10 \\
\hline Park 2015 [35] & EOSINT M270, EOS & EOS CoCr SP2, EOS & $\mathrm{T}$ & S & 25 & MG & SR & 10 \\
\hline Tamac 2014 [37] & EOSINT M270, EOS & EOS CoCr SP2, EOS & $\mathrm{T}$ & S & 30 & MG & SR & 20 \\
\hline Kim 2013 [39] & EOSINT M270, EOS & EOS CoCr SP2, EOS & $\mathrm{T}$ & S & 30 & MG & SR & 10 \\
\hline Kaleli 2017 [29] & EOSINT M270, EOS & $\begin{array}{l}\text { Keramit N/P-S, } \\
\text { Nobil Metal }\end{array}$ & $\mathrm{T}$ & M & 20 & MG & DO & 24 \\
\hline Kim 2013 [38] & EOSINT M270, EOS & EOS CoCr SP2, EOS & $\mathrm{T}$ & M & 30 & $\begin{array}{l}\text { MG, } \\
\text { AMD }\end{array}$ & SR & 10 \\
\hline Hong 2019 [23] & $\mathrm{M} 1, \mathrm{CL}$ & Remanium Star CL, CL & I & S & $\mathrm{N} / \mathrm{P}$ & $\begin{array}{l}\text { MG, } \\
\text { AMD }\end{array}$ & SR & 20 \\
\hline Gunsoy 2016 [31] & M1, CL & $\mathrm{N} / \mathrm{P}$ & $\mathrm{T}$ & S & 50 & MG & DO & 16 \\
\hline Lövgren 2017 [28] & Mlab cusing, CL & $\mathrm{N} / \mathrm{P}$ & $\mathrm{T}$ & $S$ & 50 & MG & SR & 12 \\
\hline Presotto 2019 [22] & Mlab cusing, CL & Remanium Star CL, CL & I & M & $\mathrm{N} / \mathrm{P}$ & MG & DO & 10 \\
\hline Ates 2016 [32] & $\mathrm{N} / \mathrm{P}, \mathrm{CL}$ & N/P, Dentaurum & $\mathrm{T}$ & $\mathrm{S}$ & 30 & MG & DO & 10 \\
\hline Huang 2015 [36] & $\begin{array}{l}\text { Medifacturing System, } \\
\text { Bego }\end{array}$ & Wirobond C+, Bego & $\mathrm{T}$ & S & 70 & MG & SR & 110 \\
\hline Zeng 2015 [33] & $\begin{array}{l}\text { Medifacturing System, } \\
\text { Bego }\end{array}$ & Wirobond C+, Bego & $\mathrm{T}$ & $S$ & $\mathrm{~N} / \mathrm{P}$ & MG & SR & 15 \\
\hline Arora 2018 [26] & Pro $X, 100 D P$ & $\mathrm{~N} / \mathrm{P}$ & $\mathrm{T}$ & S & $\mathrm{N} / \mathrm{P}$ & MG & DO & 10 \\
\hline Pompa 2015 [34] & N/P, DeguDent & Starloy LS, DeguDent & $\mathrm{T}$ & M & 20 & MG & MS & 20 \\
\hline Castillo-de-Oyagüe 2012 [40] & $\begin{array}{l}\text { PM100 Dental, } \\
\text { Phenix System }\end{array}$ & ST2724G, Sint-Tech & $\mathrm{T}$ & S & $\mathrm{N} / \mathrm{P}$ & MG & DO & 10 \\
\hline Örtorp 2011 [41] & $\mathrm{N} / \mathrm{P}$, Biomain $\mathrm{AB}$ & $\mathrm{N} / \mathrm{P}$ & $\mathrm{T}$ & M & 50 & MG & MS & 8 \\
\hline
\end{tabular}

$\mathrm{Ab}$-abutment; $\mathrm{CL}$-concept laser; I-implant; T—tooth; S—single; M-multi; MG—marginal gap; AMD—absolute marginal discrepancy; SR-silicone replica technique; DO-direct observation; MS-mechanical sectioning; $\mathrm{CD}$-computer-aided digital technique; $\mathrm{N} / \mathrm{P}$-not provided; $\mathrm{N}$ - number of specimen. 


\subsection{Quality Assessment and Applicability Concerns}

Figure 2 shows the results of the quality assessment using QUADAS-2. Of the 21 articles, 10 exhibited a low risk of bias [21,24,28-30,32,34,36-38], and 11 articles showed some level of unclear risk of bias $[22,23,25-27,31,33,35,39-41]$. All the included studies had a clearly stated purpose and included a control group for the evaluation of the marginal fit. There was major bias in patient selection due to the high number of studies that did not clearly justify the sample size calculation and random sampling. Randomization was not considered necessary because both 3D printing and casting methods were applied to identical specimens, preventing an increase in selection bias. With respect to the index and reference test domains, most studies provided adequate detailed information about the fabrication procedures, parameters, and devices. However, several studies did not explicitly provide the product name of the alloy $[26,27,31,32,41]$ and the setting of cementation space $[22,23,26,33,40]$. With respect to the flow and timing domain, all the studies clearly reported the measurement methods, positions, and the number of measurement points per specimen. Strategies for achieving measurement reproducibility $[24,26,29,30,32,38,40]$ and blinding tests $[22,36,37,40]$ were provided in several studies to mitigate bias opportunities.

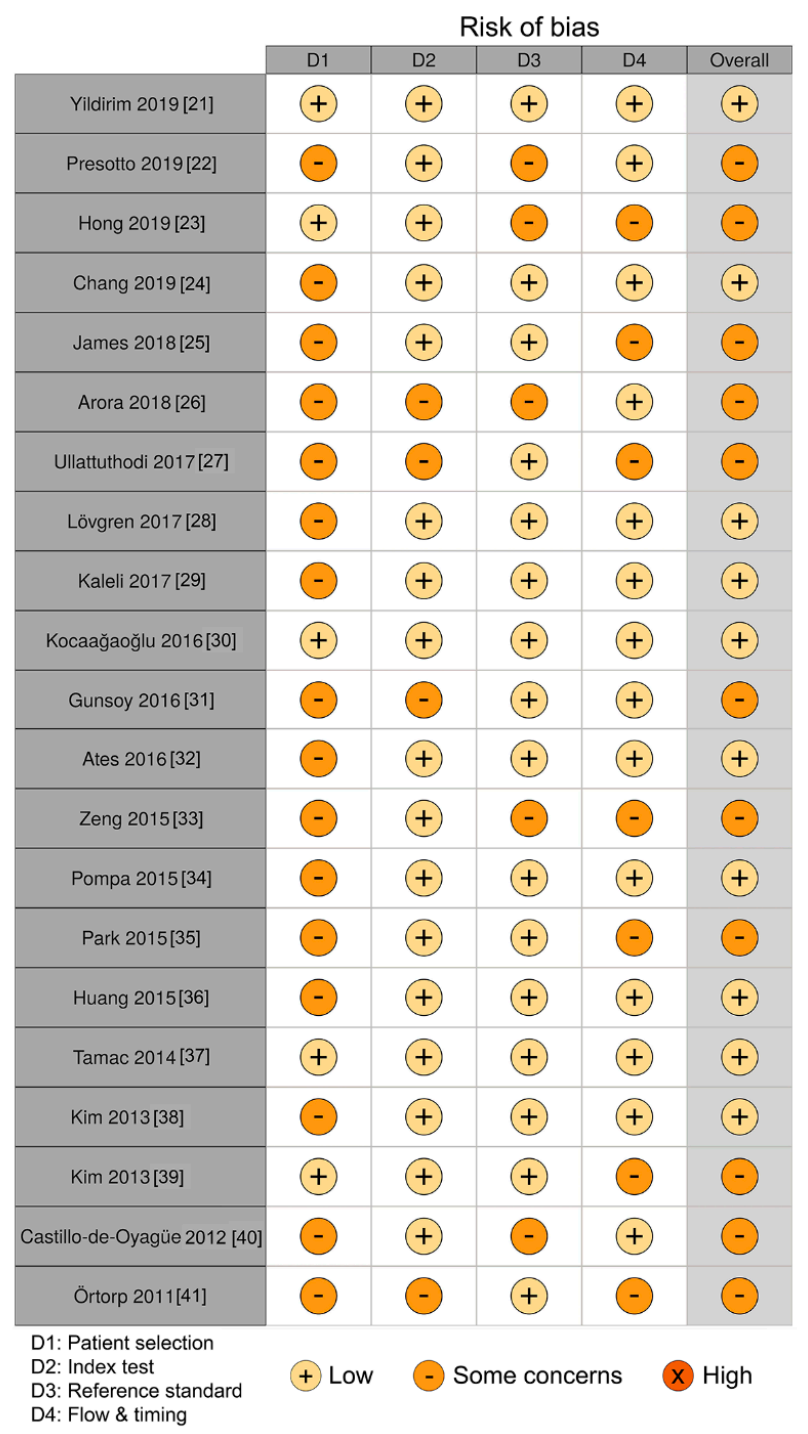

Figure 2. Quality assessment results according to the Quality Assessment Tool for Diagnostic Accuracy Studies-2 (QUADAS-2). 


\subsection{Meta-Analysis}

In the global analysis, a random effects model was applied to analyze the outcomes of all the studies, considering the heterogeneity among them. The overall SMDs of the marginal gap for two fabrication methods are shown in Figure 3. Pooled analysis revealed that the value of the marginal gap was significantly smaller in the prostheses fabricated with $3 \mathrm{D}$ printing methods rather than those made using the casting methods [SMD (95\% CI): $-0.92(-1.45,-0.38) ; Z=-3.37 ; p=0.0008]$.

\begin{tabular}{|c|c|c|c|}
\hline \multirow[b]{2}{*}{ Study } & \multicolumn{3}{|c|}{ 3D printing } \\
\hline & $\mathbf{N}$ & Mean & SD \\
\hline Yildirim 2019 [21] & 12 & 102.1 & 20.8 \\
\hline Presotto 2019 [22] & 10 & 8.4 & 3.2 \\
\hline Presotto 2019 [22] & 10 & 6.9 & 2.1 \\
\hline Hong $2019[23]$ & 10 & 143.6 & 10.4 \\
\hline Hong 2019 [23] & 10 & 141.2 & 15.9 \\
\hline Chang 2019 [24] & 10 & 115.3 & 91.8 \\
\hline James 2018 [25] & 10 & 103.1 & 7.3 \\
\hline Arora 2018 [26] & 10 & 78.3 & 7.0 \\
\hline Ullattuthodi 2017 [27] & 10 & 109.9 & 29.9 \\
\hline Lövgren 2017 [28] & 12 & 53.0 & 19.0 \\
\hline Kaleli 2017 [29] & 24 & 49.0 & 2.0 \\
\hline Kocaağaoğlu 2016 [30] & 10 & 72.7 & 14.5 \\
\hline Gunsoy 2016 [31] & 16 & 51.6 & 11.0 \\
\hline Gunsoy 2016 [31] & 16 & 39.5 & 9.8 \\
\hline Ates 2016 [32] & 10 & 32.1 & 14.2 \\
\hline Ates 2016 [32] & 10 & 27.6 & 6.4 \\
\hline Zeng 2015 [33] & 15 & 36.0 & 11.0 \\
\hline Pompa 2015 [34] & 20 & 45.2 & 16.4 \\
\hline Pompa 2015 [34] & 20 & 50.4 & 18.9 \\
\hline Park 2015 [35] & 10 & 71.0 & 19.6 \\
\hline Huang 2015 [36] & 110 & 75.6 & 32.6 \\
\hline Tamac 2014 [37] & 20 & 96.2 & 26.9 \\
\hline Kim 2013 [38] & 10 & 132.1 & 60.5 \\
\hline Kim 2013 [38] & 10 & 128.0 & 68.8 \\
\hline $\operatorname{Kim} 2013$ [39] & 10 & 75.0 & 9.9 \\
\hline Castillo-de-Oyagüe 2012 [40] & 10 & 27.2 & 8.4 \\
\hline Castillo-de-Oyagüe 2012 [40] & 10 & 61.6 & 7.5 \\
\hline Castillo-de-Oyagüe 2012 [40] & 10 & 55.7 & 5.9 \\
\hline & 8 & 69.5 & 31.5 \\
\hline \multirow[t]{2}{*}{ Örtorp 2011[41] } & 8 & 110.0 & 41.5 \\
\hline & 461 & & \\
\hline
\end{tabular}

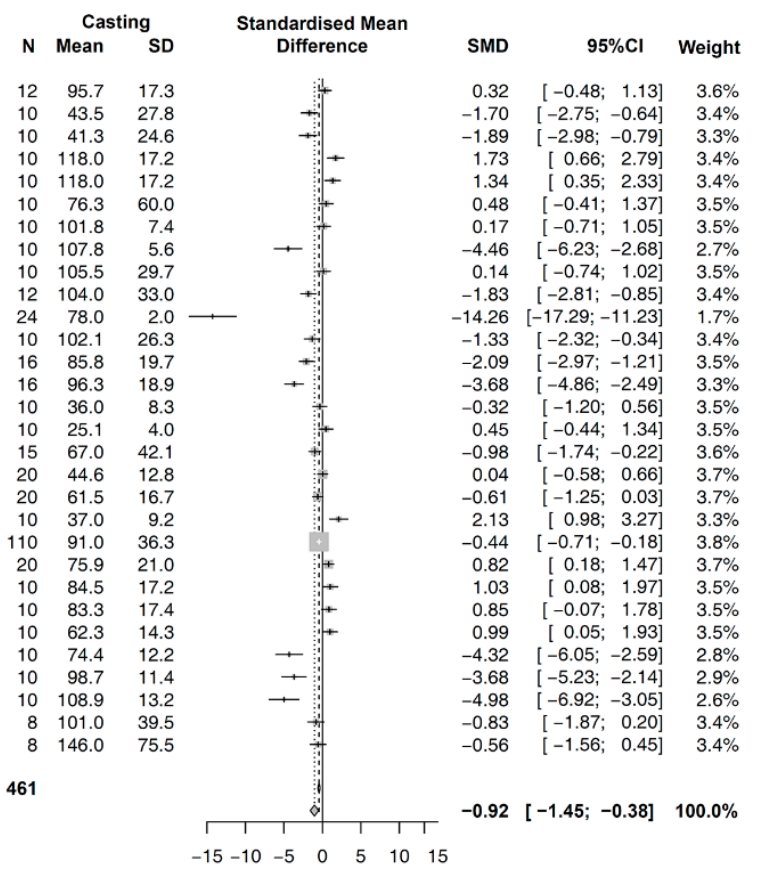

Figure 3. Global meta-analysis on the marginal gap of prostheses fabricated with 3D printing versus casting methods.

The first subgroup analysis was performed for different types of prosthesis. There was no significant difference noted in the estimated SMD between single and multi-unit types $(p=0.3573)$. Within the subgroups, the results in the random effects model are as follows (Figure 4): single type [SMD (95\% CI): $-0.7700(-1.3871,-0.1529) ; \mathrm{Z}=-2.45 ; p=0.0145]$ and multi-unit type [SMD (95\% CI): $-1.3938(-2.5697,-0.2178) ; Z=-2.32 ; p=0.0202]$.

The second subgroup analysis was conducted for the different measurement methods of the marginal fit. There was a significant difference between the subgroups of the direct observation and the silicone replica technique $(p<0.001)$. Within the subgroups, results in the random effects model yielded the following data (Figure 5): direct observation [SMD (95\% CI): $-3.0735(-4.3947,-1.7523)$; $Z=-4.56 ; p<0.001]$ and the silicone replica technique [SMD (95\% CI): $0.3379(-0.2331,-0.9088)$; $\mathrm{Z}=1.16 ; p=0.2461]$. 


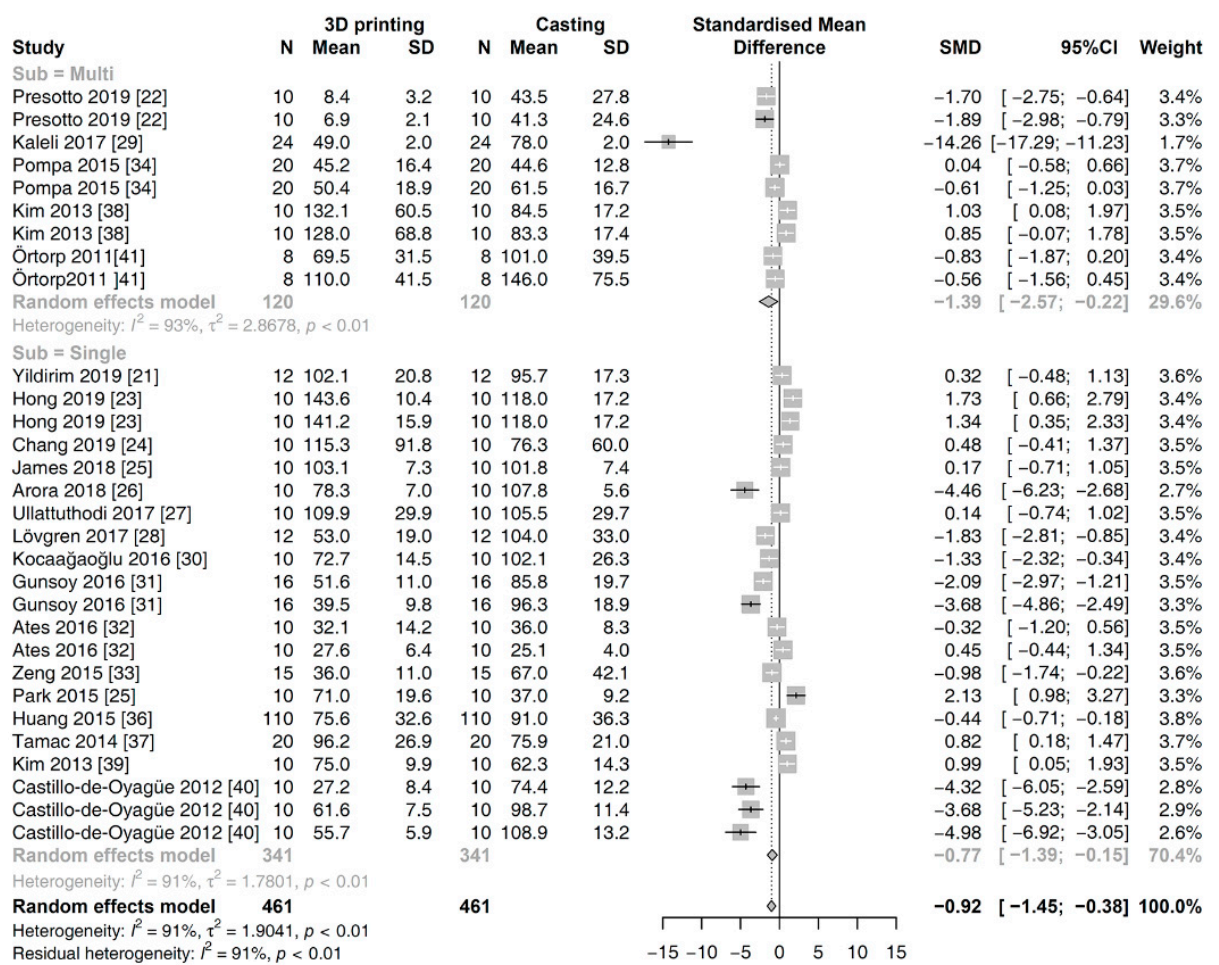

Figure 4. Subgroup meta-analysis for the different prosthesis types on the marginal gap between 3D printing and casting methods.

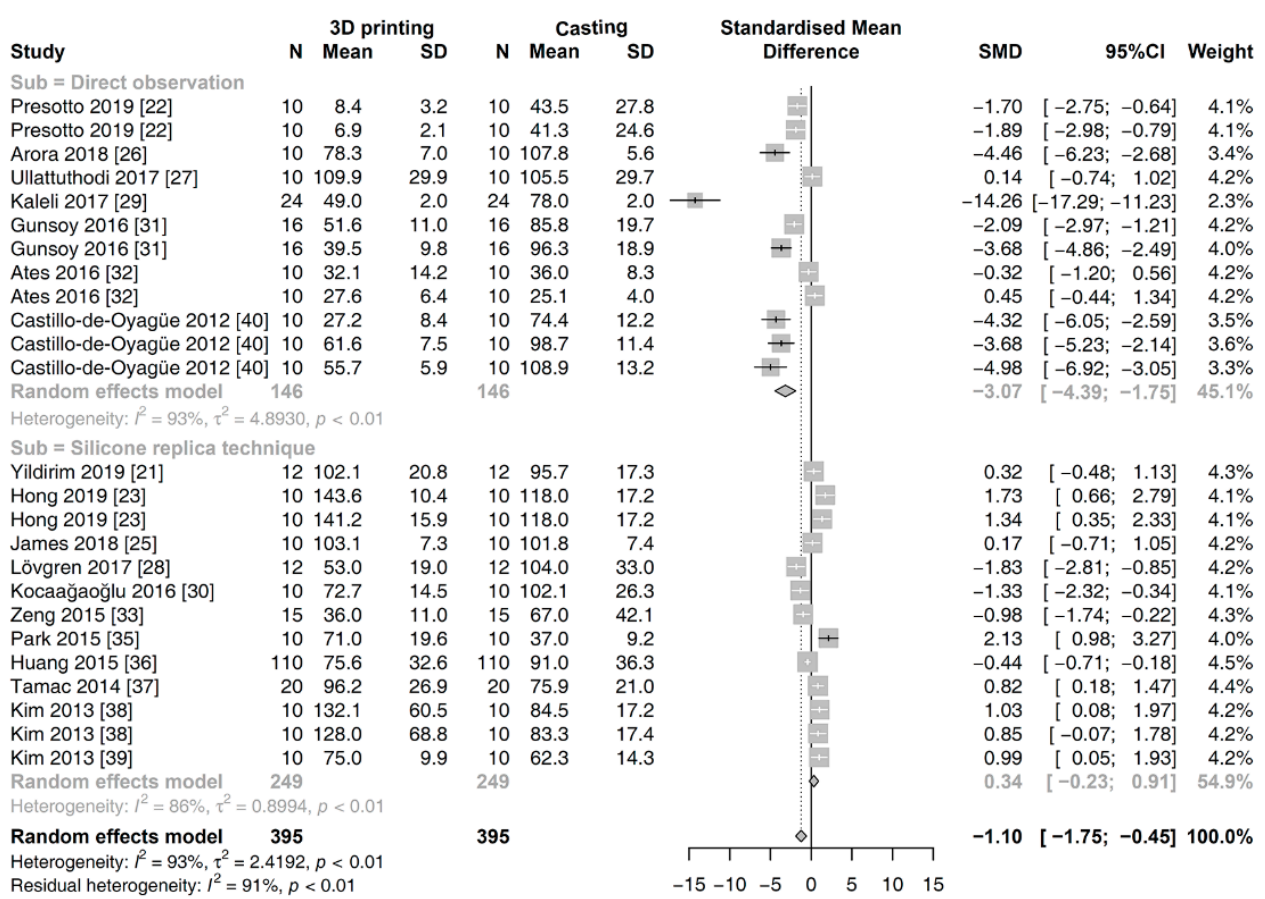

Figure 5. Subgroup meta-analysis for the different measurement methods on the marginal gap between 3D printing and casting methods.

Funnel plotting and Egger's regression test showed a moderate risk of publication bias for both global analyses $(p=0.0528$ ) (Figure 6). Accordingly, a random effects model was used to evaluate the SMD results. 


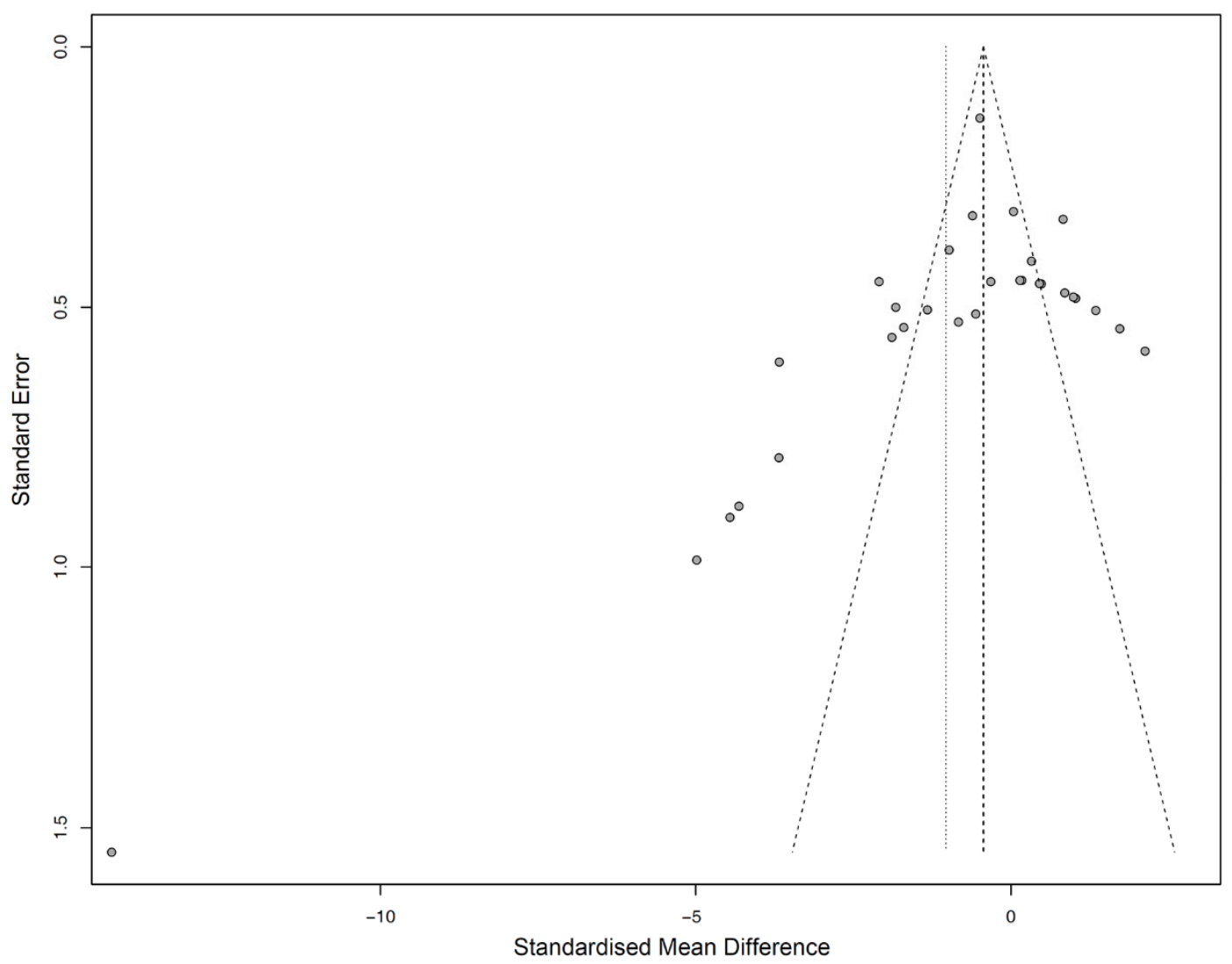

Figure 6. Funnel plot showing publication bias assessment.

\section{Discussion}

This review is aimed at assessing the marginal fit of 3D-printed Co-Cr fixed dental prostheses based on previous original articles. Studies that discussed both 3D printing and conventional casting were systematically selected for a comparative analysis, and statistical meta-analyses were then performed. The results from this review reveal that the marginal gap values of prostheses manufactured with 3D printing were significantly smaller than those of prostheses fabricated using casting methods. Thus, 3D printing technology appears to be capable of providing results comparable or even better than those achieved using prostheses utilizing established fabrication techniques in terms of the marginal accuracy; thus, 3D printing technology can be used as an alternative manufacturing modality. The present results correspond well with earlier narrative reviews wherein the marginal fit of metal frameworks fabricated using $3 \mathrm{D}$ printing was within the clinically accepted range [6,7]. To our knowledge, this is the first meta-analysis to compare the 3D printing methods with conventional methods for evaluating the fit of fixed dental prostheses.

The subgroup meta-analysis on the different types of prosthesis presented no significant difference in terms of the estimated SMD between single crowns and multi-unit prostheses. Thus, the 3D-printed prostheses had a better marginal fit than the prostheses fabricated using casting methods, irrespective of the size. Meanwhile, in the subgroup meta-analysis on the measurement methods, the tendency of marginal discrepancy between the 3D printing and casting groups was significantly different between articles that used the direct observation and the silicone replica technique. In the articles with the direct observation, large differences in the misfit were found between the 3D printing and casting groups $(\mathrm{SMD}=-3.0735, p<0.001)$. However, within the comparison of the articles with the silicone replica technique, the difference in the misfit between the 3D printing and casting groups was non-significant $(\mathrm{SMD}=0.3379, p=0.2461)$. This finding might be related to the measurement procedure and reliability in the testing methods of the studies [42]. The silicone replica technique is the most commonly used nondestructive method that is applicable in the clinical setting; however, its major drawback 
is its susceptibility to error [43]. The thin silicone layer in the margin area can be torn or distorted during silicone replica formation. The sectioning of the silicone replica could also be problematic because of human error when the cutting position is inconsistent or the cutting is conducted in oblique planes. When the section is not standardized, the measurements are unreliable [44]. Specific sectioning strategies, such as the use of fiducial markers or cutting devices, have been suggested in several studies to help reduce the possibility of sectioning error $[26,29,32,38,40]$. Reading error is another issue among observers during the manual selection of measurement points to measure the marginal gap in the acquired images [45]. Thus, suitable standardized procedures are necessary to increase the reliability and reproducibility of the outcomes of individual experiment studies and minimize the bias risk in the meta-analysis performed on the studies.

The fabrication of prostheses via 3D printing begins with the process of digitizing the surface of the prepared abutments with laboratory-based or intraoral optical scanners [46,47]. The scanned image is transferred to a computer design software where the prosthesis is designed. Thereafter, the design is virtually sliced and placed with support structures within the build platform in the computer manufacturing software. In the printing phase, the final prosthesis is manufactured using a stepwise metal powder supply and a laser fusion process. Finally, heat treatment is performed to relieve the internal stress caused by thermal gradients during the whole 3D printing process [48]. The final misfit of 3D-printed prostheses represents the summation of the errors involved in all the steps from the image acquisition to the post-treatment process. Compared to conventional methods, although the digital workflow allows the elimination of inherent inaccuracies related to laboratory manual works, different devices and parameters can highly influence the dimensional accuracy of outcome products [9]. The quality of optical scanners and scan protocols also affect the accuracy of digitization. Technical parameters defined in printing, such as energy source, energy power, laser beam absorption/reflection coefficients, chamber condition, build orientation, layer thickness, and support generation, are all important [10]. The diversity in the manufacturing parameters makes it difficult to make assertive conclusions in the review. Thus, a detailed protocol that discloses all the manufacturing parameters of 3D printing process should be provided to analyze the reliability of a specific 3D printing method, because these factors are commonly interrelated and determine the product quality.

Powder bed fusion technologies use a high-power laser that selectively melts the pre-alloyed powders, following the design of the product, and then partially melts the previous powder layer [2]. The consecutive melting and solidifying of material powders enables interlayer fusion for the completion of the product [8]. Powders for the powder bed fusion are typically produced using gas atomization processes [49]. Spherical particles with a smooth surface and Gaussian size distribution are especially recommended because the spherical shape increases the powder flowability, resulting in higher uniformity and density of powder beds [50]. As the laser beam is shone over the powders, solidification structures such as cells or dendrites are formed in fine and anisotropic microstructures due to the high scanning speeds and small melt pools [51]. Altogether, the particle morphology, particle size distribution, and voids between the powders affect the absorption, reflection, and penetration of the laser radiation [52-54]. Consequently, the characteristics of the powder are related to the shape of melt pools and lattice structure. Because the surface roughness and subsequent surface treatment could influence the adaptation of the printed fixed dental prostheses [55,56], it may be necessary to appropriately select powders for the fabrication of dental prostheses.

Close adaptation between mechanical components of implant is essential to minimize biologic and prosthetic complications. The micro gap at the implant-abutment connection is also an important factor that could cause peri-implantitis, and the relationship between the implant-abutment connection and bacterial leakage has been reported in a review [57]. Further meta-analysis on the micro gap and resultant complications might be recommended. In the present review, a meta-analysis on the effects of scanning, printing, and post-treatment conditions could not be performed because the related information was not sufficiently described in the included studies. Most studies reporting on the accuracy of 3D-printed metal frameworks were in vitro studies that involved a bias risk in the 
justification of the sample size and the random allocation of specimens. We could identify few eligible clinical studies. Therefore, randomized controlled clinical trials will be needed to strengthen the power of review articles. Moreover, considering the rapid development in the fields of technology and material, further original studies with newly developed devices and materials need to be continuously pursued to establish knowledge as per the present times.

\section{Conclusions}

Within the limitations of this systematic review and meta-analysis, the following conclusions were drawn:

1. Metal 3D printing technologies are reliable for fabricating Co-Cr-based fixed dental prostheses with an accurate marginal fit, as compared to conventional casting methods.

2. The difference in methodology for evaluating the marginal fit could influence the results in comparative studies.

3. Further controlled laboratory and clinical studies with a detailed protocol that discloses all the manufacturing parameters are needed to statistically analyze the factors affecting the accuracy of 3D-printed prostheses.

Author Contributions: Conceptualization, S.B. and D.-H.L.; methodology, M.-H.H. and H.L.; data curation, S.B., J.L., C.-H.L. and M.H.; formal analysis, H.L. and J.L.; investigation, M.-H.H., C.-H.L., M.H. and D.-H.L.; writing —original draft preparation, S.B.; writing—review and editing, M.-H.H., H.L., C.-H.L., M.H., J.L. and D.-H.L.; supervision, D.-H.L. All authors have read and agreed to the published version of the manuscript.

Funding: This research received no external funding.

Conflicts of Interest: The authors declare no conflict of interest.

\section{References}

1. Korner, M.E.H.; Lambán, M.P.; Albajez, J.A.; Santolaria, J.; Ng Corrales, L.D.C.; Royo, J. Systematic Literature Review: Integration of Additive Manufacturing and Industry 4.0. Metals 2020, 10, 1061. [CrossRef]

2. Akhila, A.S.; Nandakishore, B.; Miriam, M.; Anil, S.K.; Abhinav, M.; Fares, A. Rapid prototyping: An innovative technique in prosthodontics. Int. J. Prev. Clin. Dent. Res. 2019, 6, 46. [CrossRef]

3. Fan, D.; Li, Y.; Wang, X.; Zhu, T.; Wang, Q.; Cai, H.; Li, W.; Tian, Y.; Liu, Z. Progressive 3D Printing Technology and Its Application in Medical Materials. Front. Pharmacol. 2020, 11, 122. [CrossRef] [PubMed]

4. Wang, H.; Lim, J.Y. Metal-ceramic bond strength of a cobalt chromium alloy for dental prosthetic restorations with a porous structure using metal 3D printing. Comput. Biol. Med. 2019, 112, 103364. [CrossRef] [PubMed]

5. Razavykia, A.; Brusa, E.; Delprete, C.; Yavari, R. An Overview of Additive Manufacturing Technologies-A Review to Technical Synthesis in Numerical Study of Selective Laser Melting. Materials 2020, 13, 3895. [CrossRef]

6. Revilla-León, M.; Meyer, M.J.; Özcan, M. Metal additive manufacturing technologies: Literature review of current status and prosthodontic applications. Int. J. Comput. Dent. 2019, 22, 55-67.

7. Alharbi, N.; Wismeijer, D.; Osman, R.B. Additive Manufacturing Techniques in Prosthodontics: Where Do We Currently Stand? A Critical Review. Int. J. Prosthodont. 2017, 30, 474-484. [CrossRef]

8. Revilla-León, M.; Sadeghpour, M.; Özcan, M. A Review of the Applications of Additive Manufacturing Technologies Used to Fabricate Metals in Implant Dentistry. J. Prosthodont. 2020, 29, 579-593. [CrossRef]

9. Konieczny, B.; Szczesio-Wlodarczyk, A.; Sokolowski, J.; Bociong, K. Challenges of Co-Cr Alloy Additive Manufacturing Methods in Dentistry-The Current State of Knowledge (Systematic Review). Materials 2020, 13, 3524. [CrossRef]

10. Koutsoukis, T.; Zinelis, S.; Eliades, G.; Al-Wazzan, K.; Al Rifaiy, M.; Al Jabbari, Y.S. Selective Laser Melting Technique of Co-Cr Dental Alloys: A Review of Structure and Properties and Comparative Analysis with Other Available Techniques. J. Prosthodont. 2015, 24, 303-312. [CrossRef]

11. Wang, J.-H.; Ren, J.; Liu, W.; Wu, X.-Y.; Gao, M.-X.; Bai, P. Effect of Selective Laser Melting Process Parameters on Microstructure and Properties of Co-Cr Alloy. Materials 2018, 11, 1546. [CrossRef] 
12. Takaichi, A.; Suyalatu; Nakamoto, T.; Joko, N.; Nomura, N.; Tsutsumi, Y.; Migita, S.; Doi, H.; Kurosu, S.; Chiba, A.; et al. Microstructures and mechanical properties of Co-29Cr-6Mo alloy fabricated by selective laser melting process for dental applications. J. Mech. Behav. Biomed. Mater. 2013, 21, 67-76. [CrossRef]

13. Svanborg, P.; Hjalmarsson, L. A systematic review on the accuracy of manufacturing techniques for cobalt chromium fixed dental prostheses. Biomater. Investig. Dent. 2020, 7, 31-40. [CrossRef]

14. Nascimento, C.D.; Ikeda, L.N.; Pita, M.S.; E Silva, R.C.P.; Pedrazzi, V.; de Albuquerque Junior, R.F.; Ribeiro, R.F. Marginal fit and microbial leakage along the implant-abutment interface of fixed partial prostheses: An in vitro analysis using Checkerboard DNA-DNA hybridization. J. Prosthet. Dent. 2015, 114, 831-838. [CrossRef] [PubMed]

15. Rossetti, P.H.O.; Valle, A.L.D.; De Carvalho, R.M.; De Goes, M.F.; Pegoraro, L.F. Correlation between margin fit and microleakage in complete crowns cemented with three luting agents. J. Appl. Oral Sci. 2008, 16, 64-69. [CrossRef] [PubMed]

16. Moher, D.; Liberati, A.; Tetzlaff, J.; Altman, D.G.; The PRISMA Group. Preferred Reporting Items for Systematic Reviews and Meta-Analyses: The PRISMA Statement. PLoS Med. 2009, 6, e1000097. [CrossRef]

17. Phillips, B.; X, H.; J, L.; D, D.-F. Faculty Opinions recommendation of Evaluation of PICO as a knowledge representation for clinical questions. Fac. Opin. Post-Publ. Peer Rev. Biomed. Lit. 2007, 2006, 359-363. [CrossRef]

18. Whiting, P.F.; Rutjes, A.W.; Westwood, M.E.; Mallett, S.; Deeks, J.J.; Reitsma, J.B.; Leeflang, M.M.; Sterne, J.A.; Bossuyt, P.M.M. QUADAS-2: A Revised Tool for the Quality Assessment of Diagnostic Accuracy Studies. Ann. Intern. Med. 2011, 155, 529-536. [CrossRef]

19. McGuinness, L.A.; Higgins, J.P.T. Risk-of-bias VISualization (robvis): An R package and Shiny web app for visualizing risk-of-bias assessments. Res. Synth. Methods 2020. [CrossRef] [PubMed]

20. Borenstein, M.; Hedges, L.V.; Higgins, J.P.T.; Rothstein, H.R. Introduction to Meta-Analysis; Wiley: Hoboken, NJ, USA, 2009; pp. 311-319.

21. Yildirim, B.; Paken, G. Evaluation of the Marginal and Internal Fit of Implant-Supported Metal Copings Fabricated with 3 Different Techniques: An In Vitro Study. J. Prosthodont. 2019, 28, 315-320. [CrossRef]

22. Presotto, A.G.C.; Barão, V.A.R.; Bhering, C.L.B.; Mesquita, M.F. Dimensional precision of implant-supported frameworks fabricated by 3D printing. J. Prosthet. Dent. 2019, 122, 38-45. [CrossRef] [PubMed]

23. Hong, M.-H.; Min, B.K.; Lee, D.-H.; Kwon, T.-Y. Marginal fit of metal-ceramic crowns fabricated by using a casting and two selective laser melting processes before and after ceramic firing. J. Prosthet. Dent. 2019, 122, 475-481. [CrossRef]

24. Chang, H.-S.; Peng, Y.-T.; Hung, W.-L.; Hsu, M.-L. Evaluation of marginal adaptation of Co-Cr-Mo metal crowns fabricated by traditional method and computer-aided technologies. J. Dent. Sci. 2019, 14, 288-294. [CrossRef] [PubMed]

25. James, A.E.; Umamaheswari, B.; Lakshmi, C.B.S. Comparative Evaluation of Marginal Accuracy of Metal Copings Fabricated using Direct Metal Laser Sintering, Computer-Aided Milling, Ringless Casting, and Traditional Casting Techniques: An In vitro Study. Contemp. Clin. Dent. 2018, 9, 421-426. [CrossRef]

26. Yadav, A.; Arora, A.; Upadhyaya, V.; Jain, P.; Verma, M. Comparison of marginal and internal adaptation of copings fabricated from three different fabrication techniques: An in vitro study. J. Indian Prosthodont. Soc. 2018, 18, 102. [CrossRef] [PubMed]

27. Ullattuthodi, S.; Cherian, K.P.; Anandkumar, R.; Nambiar, M.S. Marginal and internal fit of cobalt-chromium copings fabricated using the conventional and the direct metal laser sintering techniques: A comparative in vitro study. J. Indian Prosthodont. Soc. 2017, 17, 373-380. [CrossRef]

28. Lövgren, N.; Roxner, R.; Klemendz, S.; Larsson, C. Effect of production method on surface roughness, marginal and internal fit, and retention of cobalt-chromium single crowns. J. Prosthet. Dent. 2017, 118, 95-101. [CrossRef]

29. Kaleli, N.; Saraç, D. Influence of porcelain firing and cementation on the marginal adaptation of metal-ceramic restorations prepared by different methods. J. Prosthet. Dent. 2016, 117, 656-661. [CrossRef]

30. Kocaağaoğlu, H.; Kılınç, H.I.; Albayrak, H.; Kara, M. In vitro evaluation of marginal, axial, and occlusal discrepancies in metal ceramic restorations produced with new technologies. J. Prosthet. Dent. 2016, 116, 368-374. [CrossRef] 
31. Gunsoy, S.; Ulusoy, M. Evaluation of marginal/internal fit of chrome-cobalt crowns: Direct laser metal sintering versus computer-aided design and computer-aided manufacturing. Niger. J. Clin. Pr. 2016, 19, 636-644. [CrossRef]

32. Ates, S.M.; Duymus, Z.Y. Influence of Tooth Preparation Design on Fitting Accuracy of CAD-CAM Based Restorations. J. Esthet. Restor. Dent. 2016, 28, 238-246. [CrossRef] [PubMed]

33. Zeng, L.; Zhang, Y.; Liu, Z.; Wei, B. Effects of repeated firing on the marginal accuracy of Co-Cr copings fabricated by selective laser melting. J. Prosthet. Dent. 2015, 113, 135-139. [CrossRef] [PubMed]

34. Pompa, G.; Di Carlo, S.; De Angelis, F.; Cristalli, M.P.; Annibali, S. Comparison of Conventional Methods and Laser-Assisted Rapid Prototyping for Manufacturing Fixed Dental Prostheses: An In Vitro Study. BioMed Res. Int. 2015, 2015, 1-7. [CrossRef]

35. Park, J.-K.; Lee, W.-S.; Kim, H.-Y.; Kim, W.-C.; Kim, J.-H. Accuracy evaluation of metal copings fabricated by computer-aided milling and direct metal laser sintering systems. J. Adv. Prosthodont. 2015, 7, $122-128$. [CrossRef] [PubMed]

36. Huang, Z.; Zhang, L.; Zhu, J.; Zhao, Y.; Zhang, X. Clinical Marginal and Internal Fit of Crowns Fabricated Using Different CAD/CAM Technologies. J. Prosthodont. 2014, 24, 291-295. [CrossRef] [PubMed]

37. Tamac, E.; Toksavul, S.; Toman, M. Clinical marginal and internal adaptation of CAD/CAM milling, laser sintering, and cast metal ceramic crowns. J. Prosthet. Dent. 2014, 112, 909-913. [CrossRef]

38. Kim, K.-B.; Kim, W.-C.; Kim, H.-Y.; Kim, J.-H. An evaluation of marginal fit of three-unit fixed dental prostheses fabricated by direct metal laser sintering system. Dent. Mater. 2013, 29, e91-e96. [CrossRef]

39. Kim, K.-B.; Kim, J.-H.; Kim, W.-C.; Kim, H.-Y.; Kim, J.-H. Evaluation of the marginal and internal gap of metal-ceramic crown fabricated with a selective laser sintering technology: Two- and three-dimensional replica techniques. J. Adv. Prosthodont. 2013, 5, 179-186. [CrossRef]

40. Castillo-Oyagüe, R.; Turrión, A.S.; Lozano, J.F.L.; Albaladejo, A.; Torres-Lagares, D.; Montero, J.; Suárez-García, M.-J. Vertical misfit of laser-sintered and vacuum-cast implant-supported crown copings luted with definitive and temporary luting agents. Med. Oral Patol. Oral Cir. Bucal 2012, 17, e610-e617. [CrossRef]

41. Örtorp, A.; Jönsson, D.; Mouhsen, A.; Von Steyern, P.V. The fit of cobalt-chromium three-unit fixed dental prostheses fabricated with four different techniques: A comparative in vitro study. Dent. Mater. 2011, 27, 356-363. [CrossRef]

42. Nawafleh, N.A.; Mack, F.; Evans, J.; Mackay, J.; Hatamleh, M.M. Accuracy and Reliability of Methods to Measure Marginal Adaptation of Crowns and FDPs: A Literature Review. J. Prosthodont. 2013, 22, 419-428. [CrossRef]

43. Lee, D.-H. Digital approach to assessing the 3-dimensional misfit of fixed dental prostheses. J. Prosthet. Dent. 2016, 116, 836-839. [CrossRef] [PubMed]

44. Schlenz, M.A.; Vogler, J.A.H.; Schmidt, A.; Rehmann, P.; Wöstmann, B. Chairside measurement of the marginal and internal fit of crowns: A new intraoral scan-based approach. Clin. Oral Investig. 2019, 24, 2459-2468. [CrossRef] [PubMed]

45. Mai, H.-N.; Lee, K.E.; Ha, J.-H.; Lee, D.-H. Effects of image and education on the precision of the measurement method for evaluating prosthesis misfit. J. Prosthet. Dent. 2018, 119, 600-605. [CrossRef]

46. Barrios-Muriel, J.; Romero-Sánchez, F.; Alonso, F.J.; Salgado, D.R. Advances in Orthotic and Prosthetic Manufacturing: A Technology Review. Materials 2020, 13, 295. [CrossRef]

47. Oropallo, W.; Piegl, L.A. Ten challenges in 3D printing. Eng. Comput. 2015, 32, 135-148. [CrossRef]

48. Huang, Z.; Zhang, X.; Zhu, J.; Zhang, X. Clinical marginal and internal fit of metal ceramic crowns fabricated with a selective laser melting technology. J. Prosthet. Dent. 2015, 113, 623-627. [CrossRef]

49. Franz, H.; Plöchl, L.; Schimansky, F.-P. Recent advances of titanium alloy powder production by ceramic-free inert gas atomization. In Proceedings of the 24th Annual International Titanium Associaction Conference Titatnium 2008, Las Vesgas, NV, USA, 21-24 September 2008.

50. Gu, D.; Meiners, W.; Wissenbach, K.; Poprawe, R. Laser additive manufacturing of metallic components: Materials, processes and mechanisms. Int. Mater. Rev. 2012, 57, 133-164. [CrossRef]

51. Murr, L.E.; Gaytan, S.M.; Ramirez, D.A.; Martinez, E.; Hernandez, J.; Amato, K.N.; Shindo, P.W.; Medina, F.R.; Wicker, R.B. Metal Fabrication by Additive Manufacturing Using Laser and Electron Beam Melting Technologies. J. Mater. Sci. Technol. 2012, 28, 1-14. [CrossRef] 
52. Gusarov, A.V.; Yadroitsev, I.; Bertrand, P.; Smurov, I. Model of Radiation and Heat Transfer in Laser-Powder Interaction Zone at Selective Laser Melting. J. Heat Transf. 2009, 131, 072101. [CrossRef]

53. Heeling, T.; Cloots, M.; Wegener, K. Melt pool simulation for the evaluation of process parameters in selective laser melting. Addit. Manuf. 2017, 14, 116-125. [CrossRef]

54. Meier, C.; Penny, R.W.; Zou, Y.; Gibbs, J.S.; Hart, A.J. Thermophysical Phenomena in Metal Additive Manufacturing by Selective Laser Melting: Fundamentals, Modeling, Simulation, and Experimentation. Annu. Rev. Heat Transf. 2017, 20, 241-316. [CrossRef]

55. Mitteramskogler, G.; Gmeiner, R.; Felzmann, R.; Gruber, S.; Hofstetter, C.; Stampfl, J.; Ebert, J.; Wachter, W.; Laubersheimer, J. Light curing strategies for lithography-based additive manufacturing of customized ceramics. Addit. Manuf. 2014, 110-118. [CrossRef]

56. Wilkes, J.; Hagedorn, Y.; Meiners, W.; Wissenbach, K. Additive manufacturing of ZrO2-Al2O3ceramic components by selective laser melting. Rapid Prototyp. J. 2013, 19, 51-57. [CrossRef]

57. Candotto, V.; Gabrione, F.; Oberti, L.; Lento, D.; Severino, M. The role of implant-abutment connection in preventing bacterial leakage: A review. J. Biol. Regul Homeost. Agents. 2019, 33, 129-134. [PubMed]

Publisher's Note: MDPI stays neutral with regard to jurisdictional claims in published maps and institutional affiliations.

(C) 2020 by the authors. Licensee MDPI, Basel, Switzerland. This article is an open access article distributed under the terms and conditions of the Creative Commons Attribution (CC BY) license (http://creativecommons.org/licenses/by/4.0/). 